\title{
Partial weightbearing is not necessary after cementless total hip arthroplasty
}

\author{
A two-year prospective randomized study on 100 patients
}

\author{
Max Markmiller • Thomas Weiß • Peter Kreuz • \\ Axel Rüter • Gerhard Konrad
}

Received: 30 May 2010 /Revised: 23 June 2010 /Accepted: 23 June 2010 /Published online: 11 July 2010

(C) Springer-Verlag 2010

\begin{abstract}
The purpose of this study was to evaluate the effects of partial and full weightbearing after cementless total hip arthroplasty over a two year follow-up period. Fifty-nine women and 41 men (average age 61 years) received an uncemented Spotorno stem and were randomised into a full and a partial weightbearing group. No significant difference was found between the groups with regard to the Merle d' Aubigne hip score, VAS pain level, shaft migration or radiographic signs of bony ingrowth. All femoral components seemed radiologically well-fixed and showed bone ingrowth at 24 months. Provided that solid initial fixation is obtained full weightbearing immediately after cementless total hip arthroplasty using a hydroxyapatitecoated Spotorno-type femoral shaft component can be recommended.
\end{abstract}

M. Markmiller

Orthopaedic and Trauma Surgery, Klinikum Kempten,

Kempten, Germany

T. Weiß

Trauma Center Murnau,

Murnau, Germany

P. Kreuz

Orthopaedic and Trauma Surgery, Technical University Munich, Munich, Germany

A. Rüter

Orthopaedic and Trauma Surgery, Klinikum Augsburg,

Augsburg, Germany

G. Konrad $(\bowtie)$

Orthopaedic and Trauma Surgery, University Hospital Freiburg, Freiburg, Germany

e-mail: gerhard.konrad@uniklinik-freiburg.de

\section{Introduction}

Uncemented total hip arthroplasty (THA) has gained widespread acceptance due to reliable intermediate and long-term results [1-4]. Immediate weightbearing after an uncemented THA may cause micromovements at the boneimplant interface, jeopardising stability and ingrowth of the implant [5]. Pilliar et al. reported that osseous ingrowth is inhibited by excessive micromotion at the interface between implant and bone [6]. Therefore, most patients have been mobilised with partial weightbearing or nonweightbearing for four to 12 weeks after implantation of cementless femoral components [1-4].

On the other hand, functional recovery may be promoted by immediate weightbearing and periprosthetic demineralisation may be reduced [7, 8]. Ingrowth of the bone onto uncemented implants will occur after rigid initial stability is acquired at surgery [9]. Long-term follow-up data with satisfactory clinical results supported early weightbearing in patients with cementless femoral components [7, 8, 10-13]. However, most prospective studies describing the results after immediate full weightbearing after uncemented THA report the results of relatively small numbers of patients [7, 10-13].

The objective of this prospective study was to evaluate the effects of partial and full weightbearing after cementless total hip arthroplasty on the clinical and radiological results over a two-year follow-up period.

\section{Patients and methods}

One hundred consecutive patients were included in our prospective study. Patients with primary osteoarthritis or osteonecrosis of the hip necessitating a total hip arthroplasty were randomised using envelopes into a full 
weightbearing group (group F) and a partial weightbearing group (group P). Informed consent of every patient was obtained and the study was approved by the Institutional Review Board. The same surgical technique was used in every patient. Three experienced surgeons operated upon the patients in supine position using an anterior, transgluteal approach. All patients received an uncemented hydroxyapatite-coated Spotorno-type femoral shaft component and a cementless titanium-coated acetabular component. Initial mechanical stability was achieved by press fit. Patients were mobilised on the first postoperative day under supervision of experienced physiotherapists. The patients in the full weightbearing group were immediately instructed to walk without external support whenever possible. The patients in the partial weightbearing group were allowed to walk with $15 \mathrm{~kg}$ weight on the operated hip using crutches for six weeks. Both mobilisation protocols were supervised by physiotherapists. After hospital discharge every patient stayed for four weeks at a physiotherapy health centre which continued the weightbearing schedule. After six weeks all patients progressed to weightbearing as tolerated.

The patients were evaluated clinically after three months and 24 months using the Merle d' Aubigne hip score [14]. All patients were asked to assess their pain level using a visual analog pain scale. A score of 0 represents no pain and a score of 10 represents the worst imaginable pain of the patient. Bijur et al. showed that the VAS is sufficiently reliable to be used to assess acute pain [15]. The degree of mobility (ability to walk with or without aids) was assessed at both follow-up visits. Patients were also monitored for complications such as fracture, dislocation, symptomatic deep venous thrombosis and infection.

\section{Radiographic evaluation}

Standardised anteroposterior and lateral radiographs were taken immediately after the operation and at the three and 24-months follow-up visit. Blinded analysis of the radiographs was done by an orthopaedic surgeon otherwise not involved in the study. For the evaluation of possible shaft migration distance, measurements were performed between the most medial point of the lesser trochanter and the shoulder of the prosthesis [10]. The diameter of the acetabular cup was also measured on each X-ray and was used to correct differences in magnification. A migration of $5 \mathrm{~mm}$ or more in the vertical direction was considered to indicate shaft subsidence [16]. Heterotopic ossifications were assessed using the Brooker classification [17] and radiolucent lines around the femoral component were assessed using a zonal classification of the proximal femur [18].

Statistical analysis was performed using the MannWhitney U-test since the measurements of the primary parameters were not normally distributed. A $p$-value of less then 0.05 was considered significant. We used SPSS for Windows for all statistical evaluations.

\section{Results}

The patient population consisted of 59 women and 41 men (Table 1). Checking the homogeneity of the groups as a condition of their comparability showed equal distributions for sex, age and weight in the two randomised groups; the average age in our study was 61 years in both groups (range 43-75 years). With regard to the indications for surgery and the size of the implant or the mean duration of hospital stay, there were no significant differences between the two groups. Ninety-two patients (47 patients in group F and 45 patients in group P) could be examined clinically and radiologically three months after the operation. At the 24-months followup 83 patients ( 43 patients in group $\mathrm{F}$ and 40 patients in group P) could be examined. The remaining 17 patients could not be evaluated as they either were unwilling to participate further (five patients), could not be contacted (nine patients) or the patient had died (three patients).

\section{Clinical outcome}

Three months and 24 months after the operation the range of motion in the hip joint showed no significant difference between the two groups. The Merle d' Aubigne hip score at the three-months follow-up visit were 15.1 for group $\mathrm{P}$ and 15.4 for group F. After 24 months, the Merle d' Aubigne score showed a value of 17.3 for patients in group $\mathrm{P}$ and a value of 17.1 for patients in group F. There was no significant difference between the two groups at either follow-up visit.

Table 1 Demographic data

\begin{tabular}{lll}
\hline Demographic & Partial weight bearing group & Full weight bearing group \\
\hline Number of patients & 50 & 50 \\
Men/women & $19 / 31$ & $22 / 28$ \\
Age (years) & $60.6 \pm 12.5$ & $61.2 \pm 13.1$ \\
Height $(\mathrm{cm})$ & $166 \pm 8.6$ & $168 \pm 9.6$ \\
Weight $(\mathrm{kg})$ & $76 \pm 11.0$ & $80 \pm 9.1$ \\
\hline
\end{tabular}


In the VAS for assessing the pain level no significant difference could be found between the two groups at three-months (3.3 points in group $\mathrm{F}$ and 3.1 points in group $\mathrm{P}$ ) or at the 24-months follow-up (1.1 and 0.9 points, respectively).

Three months after the operation 35 of 47 patients (74\%) showed a secure and free gait, whereas 30 of 45 patients $(67 \%)$ from the partial weightbearing group were able to walk without a cane. At the 24-months follow-up 42 of 43 patients $(98 \%)$ in the full weightbearing and 39 of 40 patients $(98 \%)$ in the partial weightbearing group were mobile without a cane (Table 2).

\section{Radiological outcome}

At the three-months follow-up a shaft migration less than $2 \mathrm{~mm}$ was present in 87 patients (95\%). Three patients in group F and two patients in group P presented with a shaft migration between 2 and $4 \mathrm{~mm}$. Patients in group F showed an average shaft migration of $1.6 \pm 1.0 \mathrm{~mm}$ compared to an average shaft migration of $1.4 \pm 1.0 \mathrm{~mm}$ in group $\mathrm{P}$. The difference was not significant $(p=0.38)$. Between the threemonths and the 24-months follow-up visits no further shaft migration greater than $1 \mathrm{~mm}$ could be detected in either group. Since no migration of $5 \mathrm{~mm}$ or more was found no subsidence of the femoral shaft was considered to have occurred in either group. All femoral components seemed radiologically well-fixed and showed bone in-growth at the 24-month follow-up visit.

Fourteen patients $(33 \%)$ in the full weightbearing group and 13 patients $(33 \%)$ in the partial weightbearing group showed periarticular areas of ossification (16 Brooker type I, 7 type II and 4 type III). Radiolucent lines on the femoral side were seen in five patients in group F: three in zone 1 and two in zone 7. Radiolucent lines on the femoral side were seen in four patients in group P: two in zone 1, one in zone 2 and one in zone 7. All radiolucent lines were less than $1 \mathrm{~mm}$ wide.

\section{Complications}

Two patients in the partial weightbearing group presented with a deep vein thrombosis; this complication did not occur in the full weightbearing group. There were two patients with surgery-related complications; due to an early wound infection (Staphylococcus aureus) an operative procedure with irrigation and debridement was necessary in one patient of the partial weightbearing group. One patient of the full weightbearing group had to undergo surgical revision for a postoperative haematoma. There were no deep infections, hip dislocations or periprothetic fractures by the 24-month follow-up visit.

\section{Discussion}

There is still controversy in the literature about the optimal postoperative management after cementless total hip arthroplasty. Partial weightbearing for six to 12 weeks has often been recommended [19-22]. However, partial weightbearing may increase muscle atrophy and loss of bone mineral density, therefore inhibiting functional recovery [7]. Furthermore, the risk of deep venous thrombosis may be increased with partial weightbearing after THA [23, 24]. On the other hand unrestricted weightbearing after an uncemented THA may cause micromovements at the bone-implant interface, jeopardising stability and ingrowth of the implant [5].

The stability of cementless implants is dependent on the initial mechanical fit between the prosthetic stem and the intramedullary canal. This initial implant stability of cementless components has been increased to three times body weight using new implant designs and surface finishings [25]. Bergmann et al. reported that standing on one leg without walking aids resulted in loads of as much as $300 \%$ body weight. Therefore, from a biomechanical standpoint, immediate full weightbearing might be possible after cementless THA [26].

Immediate full weightbearing was first done in patients having bilateral uncemented THAs [27]. The authors concluded that ingrowth of bone was not adversely affected by full weightbearing if initial stability of the metaphyseal and diaphyseal portions of the femur had been achieved [27]. However, patients used two crutches for four to eight weeks, and walking aids were used for an average of 3.5 months. Rao et al. [8] compared femoral subsidence on conventional radiographs and clinical results after unilateral

Table 2 Clinical results

\begin{tabular}{|c|c|c|c|c|c|c|}
\hline \multirow[t]{2}{*}{ Group } & \multicolumn{3}{|c|}{ Three months postoperative } & \multicolumn{3}{|c|}{24 months postoperative } \\
\hline & Hip score & VAS pain level & Ability to walk without a cane & Hip score & VAS pain level & $\begin{array}{l}\text { Ability to walk without } \\
\text { a cane }\end{array}$ \\
\hline Partial weight bearing group & 15.1 & 3.1 & $30 / 45(67 \%)$ & 17.3 & 0.9 & $39 / 40(98 \%)$ \\
\hline Full weight bearing group & 15.4 & 3.3 & $35 / 47(74 \%)$ & 17.1 & 1.1 & $42 / 43(98 \%)$ \\
\hline
\end{tabular}


and simultaneous bilateral uncemented total hip arthroplasty. Immediate weightbearing after bilateral total hip arthroplasty in this study resulted in more initial subsidence of the femoral prosthesis but did not preclude the prosthesis from becoming stable and achieving bone ingrowth. Patients in both groups obtained satisfactory clinical results [8]. Jacobs and Christensen [28] investigated whether subsidence of a tapered, proximally porous- and hydroxyapatite-coated femoral implant with immediate postoperative weightbearing differs between men and women. Regardless of sex, subsidence was greater at one year than at six weeks; men subsided significantly more at one year than women.

Chan et al. [29] found that full weightbearing after uncemented THA is compatible with good clinical results and stability using conventional radiography. These data were recently supported by Strom et al. [30]. In this study 42 patients with osteoarthritis were operated up on using an uncemented CLS stem and randomised to partial or unrestricted weightbearing. The authors concluded that early full weightbearing and active rehabilitation can be used for the uncemented CLS stem without increased risk of early loosening. However, most prospective studies describing the results of immediate full weightbearing after uncemented THA included a rather small number of patients $[7,10-13,29,30]$.

We included one hundred patients in our prospective study. In accordance with the literature, our results showed no difference in the clinical outcome between patients mobilised with full weightbearing and patients mobilised with partial weightbearing after cementless total hip replacement. The radiological follow-up findings in our patients are also in conformity with the literature; no significant differences were seen that might be attributable to the early postoperative mode of weightbearing. The majority of patients in the full weightbearing group as well as in the partial weightbearing group showed a shaft migration of less than $2 \mathrm{~mm}$ within the first three months. No further shaft migration greater than $1 \mathrm{~mm}$ occurred between the threemonths and the 24-months follow-up visits in either group, indicating that the femoral stem had stabilised. A little subsidence of the uncemented CLS stem has also been reported by Strom et al. [30]. Using radiostereometric analysis they found 1.2-mm subsidence of the stem at 24 months with no significant difference in the migration pattern between the unrestricted and partial weight bearing groups.

Initial migration seems to be tolerated in the uncemented hydroxyapatite-coated stems we used in our study. This may be explained by the quality of hydroxyapatite as a biological adjuvant which enhances bone in-growth even across a gap [31]. Hydroxyapatite-coating may play an important role for early weightbearing because it induced bony in-growth into the implant despite continuous micromotion of more than $150 \mu \mathrm{m}$ [32].
Full weightbearing immediately after surgery has been reported to prevent deep venous thrombosis [23]. In our study no symptomatic deep venous thrombosis was found in the full weightbearing group compared to two deep venous thromboses in the partial weightbearing group.

It has been shown that the compliance of the patients with the recommended limited weightbearing is low [33]. We did not use a pressure-sensitive auditory device incorporated in the sole of the shoe to control the prescribed weight limit. This may be a limitation of our study. On the other hand all patients were mobilised under supervision of experienced physiotherapists during their hospital stay and after discharge every patient stayed for four weeks at a physiotherapy health centre which continued the weightbearing schedule. For the evaluation of possible shaft migration, distance measurements were performed using standardised anteroposterior and lateral radiographs. Variability in patient positioning or exposure may have led to errors in the measurement of shaft migration. We did not use roentgen stereophotogrammetry (RSA) since previous studies with uncemented hydroxyapatite-coated prostheses have shown minimal migration of the femoral component after two years $[11,12,30]$. The strengths of the study include the prospective design and the relatively high number of patients included. The radiological analysis was performed by an orthopaedic surgeon otherwise not involved in the study, removing the potential for surgeon bias.

The objective of this prospective study was to evaluate the effects of partial and full weightbearing after cementless total hip arthroplasty on the clinical and radiological results over a two-year follow-up period. No significant difference was found between the groups with regard to the Merle d' Aubigne hip score, VAS pain level, shaft migration and radiographic signs of bony ingrowth. Provided that solid initial fixation is obtained, full weightbearing immediately after cementless total hip arthroplasty using a hydroxyapatitecoated Spotorno-type femoral shaft component can be recommended.

\section{References}

1. Garcia-Cimbrelo E, Cruz-Pardos A, Madero R, Ortega-Andreu M (2003) Total hip arthroplasty with use of the cementless Zweymuller Alloclassic system. A ten to thirteen-year follow-up study. J Bone Joint Surg Am 85-A:296-303

2. Healy WL, Casey DJ, Iorio R, Appleby D (2002) Evaluation of the porous-coated anatomic hip at 12 years. J Arthroplasty $17: 856-863$

3. Kawamura H, Dunbar MJ, Murray P, Bourne RB, Rorabeck CH (2001) The porous coated anatomic total hip replacement. A ten to fourteen-year follow-up study of a cementless total hip arthroplasty. J Bone Joint Surg Am 83-A:1333-1338

4. Tanzer M, Chan S, Brooks CE, Bobyn JD (2001) Primary cementless total hip arthroplasty using a modular femoral 
component: a minimum 6-year follow-up. J Arthroplasty 16:6470

5. Radl R, Aigner C, Hungerford M, Pascher A, Windhager R (2000) Proximal femoral bone loss and increased rate of fracture with a proximally hydroxyapatite-coated femoral component. J Bone Joint Surg Br 82:1151-1155

6. Pilliar RM, Lee JM, Maniatopoulos C (1986) Observations on the effect of movement on bone ingrowth into porous-surfaced implants. Clin Orthop Relat Res 208:108-113

7. Kishida Y, Sugano N, Sakai T, Nishii T, Haraguchi K, Ohzono K, Yoshikawa H (2001) Full weight-bearing after cementless total hip arthroplasty. Int Orthop 25:25-28

8. Rao RR, Sharkey PF, Hozack WJ, Eng K, Rothman RH (1998) Immediate weightbearing after uncemented total hip arthroplasty. Clin Orthop Relat Res 349:156-162

9. Jasty M, Bragdon CR, Zalenski E, O'Connor D, Page A, Harris WH (1997) Enhanced stability of uncemented canine femoral components by bone ingrowth into the porous coatings. J Arthroplasty 12:106-113

10. Boden H, Adolphson P (2004) No adverse effects of early weight bearing after uncemented total hip arthroplasty: a randomized study of 20 patients. Acta Orthop Scand 75:21-29

11. Bottner F, Zawadsky M, Su EP, Bostrom M, Palm L, Ryd L, Sculco TP (2005) Implant migration after early weightbearing in cementless hip replacement. Clin Orthop Relat Res 436:132-137

12. Thien TM, Ahnfelt L, Eriksson M, Stromberg C, Karrholm J (2007) Immediate weight bearing after uncemented total hip arthroplasty with an anteverted stem: a prospective randomized comparison using radiostereometry. Acta Orthop 78:730-738

13. Woolson ST, Adler NS (2002) The effect of partial or full weight bearing ambulation after cementless total hip arthroplasty. J Arthroplasty 17:820-825

14. D' Aubigne RM, Postel M (1954) Function al results of hip arthroplasty with acrylic prosthesis. J Bone Joint Surg Am 36A:451-475

15. Bijur PE, Silver W, Gallagher EJ (2001) Reliability of the visual analog scale for measurement of acute pain. Acad Emerg Med 8:1153-1157

16. Malchau H, Karrholm J, Wang YX, Herberts P (1995) Accuracy of migration analysis in hip arthroplasty. Digitized and conventional radiography, compared to radiostereometry in 51 patients. Acta Orthop Scand 66:418-424

17. Brooker AF, Bowerman JW, Robinson RA, Riley LH Jr (1973) Ectopic ossification following total hip replacement. Incidence and a method of classification. J Bone Joint Surg Am 55:16291632

18. Gruen TA, McNeice GM, Amstutz HC (1979) "Modes of failure" of cemented stem-type femoral components: a radiographic analysis of loosening. Clin Orthop Relat Res 141:17-27

19. Aldinger PR, Thomsen M, Mau H, Ewerbeck V, Breusch SJ (2003) Cementless Spotorno tapered titanium stems: excellent 10-15-year survival in 141 young patients. Acta Orthop Scand $74: 253-258$

20. Jacobsen S, Jensen FK, Poulsen K, Sturup J, Retpen JB (2003) Good performance of a titanium femoral component in cementless hip arthroplasty in younger patients: 97 arthroplasties followed for 5-11 years. Acta Orthop Scand 74:375-379

21. Kim YH, Kim JS, Cho SH (1999) Primary total hip arthroplasty with a cementless porous-coated anatomic total hip prosthesis: 10to 12-year results of prospective and consecutive series. J Arthroplasty 14:538-548

22. Mont MA, Yoon TR, Krackow KA, Hungerford DS (1999) Clinical experience with a proximally porous-coated secondgeneration cementless total hip prosthesis: minimum 5-year follow-up. J Arthroplasty 14:930-939

23. Buehler KO, D'Lima DD, Petersilge WJ, Colwell CW Jr, Walker RH (1999) Late deep venous thrombosis and delayed weightbearing after total hip arthroplasty. Clin Orthop Relat Res 361:123-130

24. Leali A, Fetto J, Moroz A (2002) Prevention of thromboembolic disease after non-cemented hip arthroplasty. A multimodal approach. Acta Orthop Belg 68:128-134

25. Gotze C, Steens W, Vieth V, Poremba C, Claes L, Steinbeck J (2002) Primary stability in cementless femoral stems: custommade versus conventional femoral prosthesis. Clin Biomech (Bristol, Avon) 17:267-273

26. Bergmann G, Rohlmann A, Graichen F (1989) In vivo measurement of hip joint stress. 1. Physical therapy. Z Orthop Ihre Grenzgeb 127:672-679

27. Ritter MA, Vaughn BK, Frederick LD (1995) Single-stage, bilateral, cementless total hip arthroplasty. J Arthroplasty 10:151-156

28. Jacobs CA, Christensen CP (2009) Progressive subsidence of a tapered, proximally coated femoral stem in total hip arthroplasty. Int Orthop 33:917-922

29. Chan YK, Chiu KY, Yip DK, Ng TP, Tang WM (2003) Full weight bearing after non-cemented total hip replacement is compatible with satisfactory results. Int Orthop 27:94-97

30. Strom H, Nilsson O, Milbrink J, Mallmin H, Larsson S (2007) The effect of early weight bearing on migration pattern of the uncemented CLS stem in total hip arthroplasty. J Arthroplasty 22:1122-1129

31. Overgaard S, Lind M, Rahbek O, Bunger C, Soballe K (1997) Improved fixation of porous-coated versus grit-blasted surface texture of hydroxyapatite-coated implants in dogs. Acta Orthop Scand 68:337-343

32. Soballe K, Hansen ES, Brockstedt-Rasmussen H, Bunger C (1993) Hydroxyapatite coating converts fibrous tissue to bone around loaded implants. J Bone Joint Surg Br 75:270-278

33. Tveit M, Karrholm J (2001) Low effectiveness of prescribed partial weight bearing. Continuous recording of vertical loads using a new pressure-sensitive insole. J Rehabil Med 33:42-46 